\title{
Quality of life after aortic valve replacement with tissue and mechanical implants
}

\author{
Artyom Sedrakyan, MD \\ Patricia Hebert, $\mathrm{PhD}^{\mathrm{b}}$ \\ Viola Vaccarino, $\mathrm{MD}, \mathrm{PhD}^{\mathrm{C}}$ \\ A. David Paltiel, $\mathrm{PhD}^{\mathrm{a}}$ \\ John A. Elefteriades, MD ${ }^{\mathrm{d}}$ \\ Jennifer Mattera, MPH \\ Zhenqiu Lin, $\mathrm{PhD}^{\mathrm{e}}$ \\ Sarah A. Roumanis, $\mathrm{RN}^{\mathrm{e}}$ \\ Harlan M. Krumholz, MD
}

Objectives: We sought to determine whether changes in quality of life at 18 months following aortic valve replacement differ depending on the use of tissue valves or mechanical valves.

Methods: We prospectively studied 73 patients with tissue valve replacements and 53 patients with mechanical valve replacements performed from April 1998 through March 1999 at Yale-New Haven Hospital. Quality of life was measured at baseline and at 18 months using the Medical Outcomes Trust Short Form 36-Item Health Survey.

Results: Baseline unadjusted mean quality-of-life scores were lower in tissue valve recipients than in mechanical valve recipients and, for both groups, were generally lower than US population norms. At 18 months postoperatively, quality-of-life scores were greatly improved in both groups and were comparable to population norms (ie, within one-half a standard deviation). After adjusting for baseline quality of life, age, and other prognostic factors in an analysis of covariance, improvements in quality-of-life scores for tissue valve recipients versus mechanical valve recipients were similar. Of 10 (8 domains and 2 summary) scales examined, the only significant difference between the 2 groups was for the improvement in role limitations due to physical problems (Role Physical), which was more favorable in patients with mechanical valve implants $(P=.04)$.

Conclusions: The use of tissue valve implants versus mechanical valve implants has little influence on improvement in quality of life at 18 months following aortic valve replacement. Thus, decisions about whether to choose a tissue valve or mechanical valve implant should depend upon other factors such as rates of complications and differences in the life span of the implants.

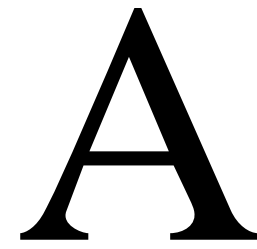

pproximately 79,000 cardiac valve surgical procedures are performed annually in the United States. ${ }^{1}$ Aortic valve replacement is the most common valve surgical procedure. Tissue or mechanical valves are implanted as substitutes for affected valves. The choice of a tissue versus mechanical valve implant involves a trade-off between the better durability of mechanical valves and the lower rate of anticoagulant-related complications associated with tissue valves. ${ }^{2-4}$

In current surgical practice, tissue valves are generally recommended for older patients, as the life span of the tissue implant is less of an issue in this group. In addition, the lower incidence of anticoagulant-related complications and slightly 
better hemodynamic characteristics associated with this type of implant make it an attractive option for older or high-risk patients who typically have more comorbidities and more advanced heart disease. However, as the longterm consequences of cardiac valve surgery extend beyond postoperative complications or survival, improvement in quality of life (QOL) is receiving more attention as an important goal of surgery. ${ }^{5-8}$ Relatively little is known about changes in QOL after aortic valve surgery and, more specifically, about differences in improvement in QOL attributed to the type of implant used. Given the differences in valve characteristics, complications, and reliability, improvement in QOL might differ when tissue or mechanical implants are used, and this information would assist surgeons and patients in choosing between the 2 types.

Most of the previous studies assessing the impact of implant type on change in QOL have been cross-sectional, thus being limited to postoperative assessment of QOL as opposed to changes in QOL from baseline..$^{5-7}$ Additionally, the 1 prospective cohort study ${ }^{9}$ had only short-term (3 months) follow-up. Other limitations included relatively small sample sizes ${ }^{9}$ and inclusion of only younger patients. ${ }^{7}$ Accordingly, the main purpose of this prospective study was to determine if there are differences in changes in QOL scores at 18 months postoperatively in tissue and mechanical valve recipients. An additional aim was to compare mean baseline and postoperative QOL scores in patients with these 2 types of implants with those of age- and gender-adjusted US population norms.

\section{Methods}

\section{Study Design and Population}

We used a prospective cohort study design. Consecutive patients $(n=189)$ undergoing isolated aortic valve or simultaneous aortic valve-coronary artery bypass graft $(\mathrm{CABG})$ procedures at YaleNew Haven Hospital, New Haven, Connecticut, from April 1, 1998, through March 30, 1999, were identified for enrollment. After consent, baseline questionnaires were completed by patients during the first week after surgery. Baseline questions were related to their functioning a month before surgery. Postoperative questionnaires were mailed to patients 18 months after the surgical procedure. The study was approved by the Human Investigation Committee of Yale University.

\section{Measurement of QOL}

We used the Medical Outcomes Trust Short Form 36-Item Health Survey (SF-36), a survey with established overall reliability and validity, ${ }^{10,11}$ to evaluate QOL. Several recent studies have also demonstrated its validity specifically in cardiovascular research. $^{12,13}$

The SF-36 consists of 36 questions, grouped into 8 multi-item domains, measuring different aspects of daily life described by Bungay and Ware ${ }^{14}$ :

1. Physical Functioning (PF) represents limitations in lifting, climbing, bending, kneeling, walking, or running.
2. Role Physical (RP) represents a degree of physical health for which a person performs activities typical for the specific age and social responsibility, such as a job, community activities, and volunteer work.

3. Bodily Pain (BP) represents the intensity and duration of bodily pain and limitations in activities due to pain.

4. General Health $(\mathrm{GH})$ represents the beliefs and evaluations of a person's overall health.

5. Vitality (VT) is a measure of feelings of energy, pep, fatigue, and tiredness.

6. Social Functioning (SF) represents the ability to develop, maintain, and nurture mature social relationships (including family, friends, and spouse).

7. Role Emotional (RE) represents personal feelings about job performance or work or other activities.

8. Mental Health (MH) represents a person's emotional, cognitive, and intellectual status.

Additionally, we used 2 meta-scores of the SF-36, the Physical Component Summary (PCS) and the Mental Component Summary (MCS). They combine 8 multi-item domains and represent global physical functioning and global mental functioning. ${ }^{15} \mathrm{We}$ compared age-adjusted US population norms with QOL following surgery. ${ }^{16,17}$

\section{Demographic and Clinical Information}

Detailed demographic and clinical information was abstracted from medical records using Society of Thoracic Surgery forms and definitions. ${ }^{18}$ Demographic variables included age and gender. Comorbidities included peripheral vascular disease (PVD), chronic obstructive pulmonary disease, diabetes, and hypertension. Heart disease-related variables were history of congestive heart failure, New York Heart Association (NYHA) functional class (III-IV versus I-II), angina, ejection fraction, cardiomegaly, chronic atrial fibrillation, previous myocardial infarction (MI), aortic stenosis, and reoperation. Procedure-related variables were implant type (tissue, mechanical) and procedure type (isolated valve replacement vs simultaneous valve and CABG).

\section{Statistical Analysis}

Analyses focused on comparing tissue and mechanical valve recipients with respect to changes in QOL scores at 18 months postoperatively. We also compared baseline and postoperative QOL scores for patients in the 2 groups with age- and genderappropriate US population norms. We defined comparability to US norms as a postoperative QOL score within one-half a standard deviation (SD) of the mean of the US norm, a clinically significant difference as reported in the SF-36 manual. ${ }^{17}$ In addition, differences of less than $0.5 \mathrm{SD}$ in magnitude are considered small according to current recommendations. ${ }^{19}$ Thus, given these reports as well as examination of distribution of the responses to QOL scales reported in the other studies, we considered 0.5 SD difference as clinically relevant for patients undergoing valve surgery.

We compared unadjusted mean pre- and postoperative QOL scores in the patients with tissue and mechanical valve replacement with US population norms using $95 \%$ confidence intervals of pre- and postoperative mean QOL scores. We had over $95 \%$ power to demonstrate a $0.5 \mathrm{SD}$ difference as statistically significant with $95 \%$ confidence. 
TABLE 1. Baseline characteristics of tissue and mechanical implant recipients

\begin{tabular}{lccc}
\hline Characteristic & $\begin{array}{c}\text { Tissue } \\
\text { implant } \\
\text { (n = 73) }\end{array}$ & $\begin{array}{c}\text { Mechanical } \\
\text { implant } \\
\text { (n = 53) }\end{array}$ & P value \\
\hline Age (mean \pm SD) & $72.8 \pm 11.3$ & $57.8 \pm 13.9$ & $<.0001$ \\
Interquartile range & $71-79$ & $47-68$ & \\
EF (mean)* & $48.7 \pm 14.7$ & $54.5 \pm 11.7$ & .028 \\
Male gender (\%) & 54.8 & 60.4 & .5 \\
Having angina & 50.7 & 47.2 & .7 \\
History of MI (\%) & 32.9 & 17.0 & .045 \\
History of CHF (\%) & 20.8 & 26.4 & .5 \\
Hypertension (\%) & 65.7 & 51.9 & .12 \\
PVD (\%) & 21.9 & 5.7 & .012 \\
COPD (\%) & 16.4 & 20.7 & .5 \\
Diabetes (\%) & 17.8 & 15.1 & .7 \\
Cardiomegaly (\%) & 41.1 & 34.0 & .4 \\
Reoperation (\%) & 11.0 & 18.8 & .2 \\
Arrhythmia (\%) $\dagger$ & 24.7 & 30.2 & .45 \\
Aortic stenosis (\%) & 93.1 & 62.3 & $<.0001$ \\
NYHA class III-IV & 67.1 & 41.5 & .003 \\
Valve + CABG & 49.3 & 28.3 & .017 \\
\hline SD Standard & &
\end{tabular}

$S D$, Standard deviation; $C A B G$, coronary artery bypass graft surgery; $C H F$, congestive heart failure; $C O P D$, chronic obstructive pulmonary disease; $E F$, ejection fraction; MI, myocardial infarction; NYHA, New York Heart Association; $P V D$, peripheral vascular disease.

*Twelve missing values.

tMostly atrial fibrillation.

‡Compared with I-II functional class.

Initially, we compared baseline characteristics for the tissue and mechanical valve recipients using the Student $t$ test for means and chi-square tests for proportions. Multivariable analysis of covariance was used to examine differences in mean changes in each of the QOL domains between patients receiving tissue and mechanical implants. In addition to the inclusion of age and gender, baseline QOL scores and NYHA functional class were the strongest predictors of changes in QOL scores and were included as covariates in the model. Other clinical characteristics were chosen on the basis of large differences in their distribution in the tissue and mechanical implant groups; these included the procedure type (isolated valve or simultaneous valve and CABG), presence of aortic stenosis, history of MI and PVD. We had $80 \%$ power to determine a $0.5 \mathrm{SD}$ difference as statistically significant with $95 \%$ confidence when comparing tissue and mechanical implant groups regarding improvement in QOL.

We used the Statistical Analysis System (SAS Institute, Cary, $\mathrm{NC}$, release 8.02) for data management and analysis.

\section{Results}

Of the 189 consecutive patients undergoing aortic valve replacement surgery during the study period, $148(78.3 \%)$ completed a baseline QOL questionnaire. Reasons for nonparticipation included death $(\mathrm{n}=8)$, language barrier $(\mathrm{n}=$ $3)$, refusal $(n=8)$, neurological problems $(n=6)$, inability to administer the QOL questionnaire before discharge $(\mathrm{n}=$ $5)$, and other reasons $(n=11)$. There were no significant
TABLE 2. Baseline 0OL scores and unadjusted improvements in OOL domains and component scales for tissue and mechanical implant recipients at $\mathbf{1 8}$ months following surgery

\begin{tabular}{|c|c|c|c|c|}
\hline \multirow[b]{2}{*}{$\begin{array}{l}\text { OOL } \\
\text { scales }\end{array}$} & \multicolumn{2}{|c|}{ Tissue implant } & \multicolumn{2}{|c|}{ Mechanical implant } \\
\hline & $\begin{array}{l}\text { Baseline } \\
\text { scores* }\end{array}$ & $\begin{array}{c}\text { Unadjusted } \\
\text { improvement }\end{array}$ & $\begin{array}{l}\text { Baseline } \\
\text { scores* }\end{array}$ & $\begin{array}{l}\text { Unadjusted } \\
\text { improvement }\end{array}$ \\
\hline PF & $46.2 \pm 27.5$ & 20.1 & $59.4 \pm 30.0$ & 19.6 \\
\hline $\mathrm{RP}$ & $20.7 \pm 34.9$ & 29.0 & $36.5 \pm 42.4$ & 43.3 \\
\hline $\mathrm{BP}$ & $64.6 \pm 30.6$ & 10.9 & $67.6 \pm 28.9$ & 17.9 \\
\hline $\mathrm{GH}$ & $55.7 \pm 12.4$ & 2.6 & $57.6 \pm 12.7$ & 2.2 \\
\hline VT & $38.3 \pm 20.7$ & 15.8 & $45.7 \pm 24.9$ & 17.0 \\
\hline SF & $69.5 \pm 25.2$ & 9.9 & $75.9 \pm 26.6$ & 8.5 \\
\hline $\mathrm{RE}$ & $62.0 \pm 45.2$ & 1.9 & $59.6 \pm 45.9$ & 18.6 \\
\hline $\mathrm{MH}$ & $57.7 \pm 12.6$ & 18.7 & $58.6 \pm 10.7$ & 16.8 \\
\hline PCS & $35.8 \pm 9.2$ & 6.9 & $40.5 \pm 9.6$ & 8.6 \\
\hline MCS & $43.0 \pm 9.0$ & 4.8 & $43.1 \pm 8.2$ & 4.9 \\
\hline
\end{tabular}

$B P$, Bodily Pain; GH, General Health; MCS, Mental Component Summary; $M H$, Mental Health; PCS, Physical Component Summary; PF, Physical Functioning; $Q 0 L$, quality of life; $R E$, Role Emotional; $R P$, Role Physical; $S F$, Social Functioning; $V T$, Vitality.

There were less than $3 \%$ missing values for some of the scales.

*Unadjusted baseline scores (mean $\pm \mathrm{SD}$ ).

differences between the participants and nonparticipants with regard to age, gender, or type of implant (data not shown). Of the 148 patients enrolled, 11 (tissue valve patients) died before 18 months of follow-up. In the remaining 137 patients, the follow-up rate was $91.9 \%$ (126/137). Three patients refused to complete the QOL questionnaire postoperatively, 5 were lost to follow-up, and $3 \mathrm{did}$ not return the questionnaire within the allotted 6-week time period. Thus, 126 patients (73 [96\% follow-up] with tissue and 53 [87\% follow-up] with mechanical implants) had both baseline and postoperative QOL assessments.

As shown in Table 1, patients receiving tissue implants were older than those receiving mechanical implants (mean age 73 years vs 58 years) and they had more comorbidities. Differences in age and comorbidities between patients with tissue and mechanical implants were reflected in the mean unadjusted baseline QOL scores. As shown in Table 2, unadjusted mean baseline QOL scores tended to be lower in patients with tissue implants and were significantly lower than those of patients with mechanical implants for the domains of PF, RP, and PCS.

In both groups, QOL at 18 months after surgery was substantially improved in most domains. Trends in absolute improvements (unadjusted) in QOL scores from the baseline were similar in the tissue and mechanical valve groups (Table 2 and Figures 1 and 2). The few domains in which there seemed to be very little absolute improvement from baseline included GH and RE in the tissue implant group and $\mathrm{GH}$ in the mechanical implant group. In the domains of $\mathrm{RP}$ and RE, there was a tendency toward greater improve- 


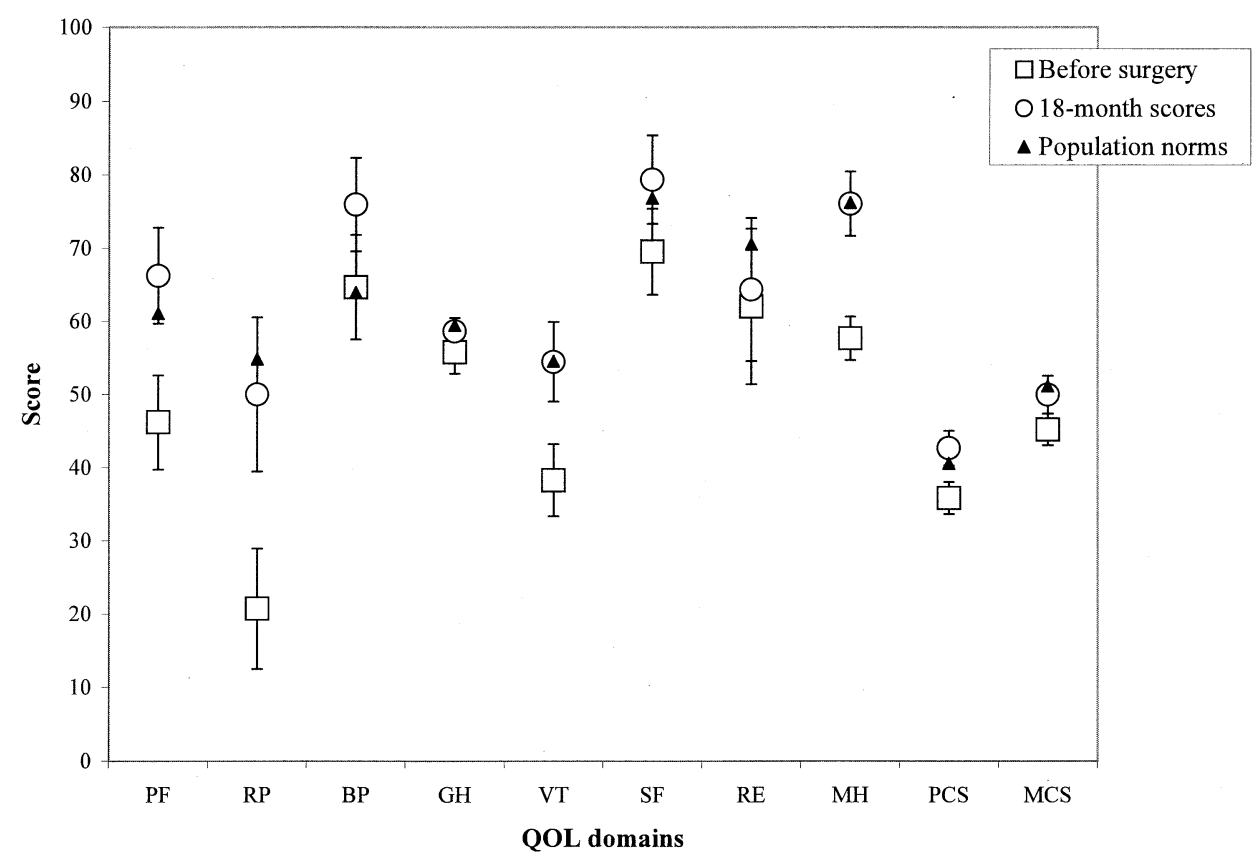

Figure 1. Unadjusted $\mathrm{OOL}$ scores with $95 \%$ confidence intervals in patients receiving tissue implants. White boxes represent preoperative $0 \mathrm{OL}$ scores, white circles represent 18-month follow-up $00 \mathrm{~L}$ scores, and black triangles represent US age-adjusted population norms for tissue implant group. BP, Bodily Pain; GH, General Health; MCS, Mental Component Summary; $M H$, Mental Health; PCS, Physical Component Summary; PF, Physical Functioning; QOL, quality of life; $R E$, Role Emotional; $R P$, Role Physical; SF, Social Functioning; VT, Vitality.

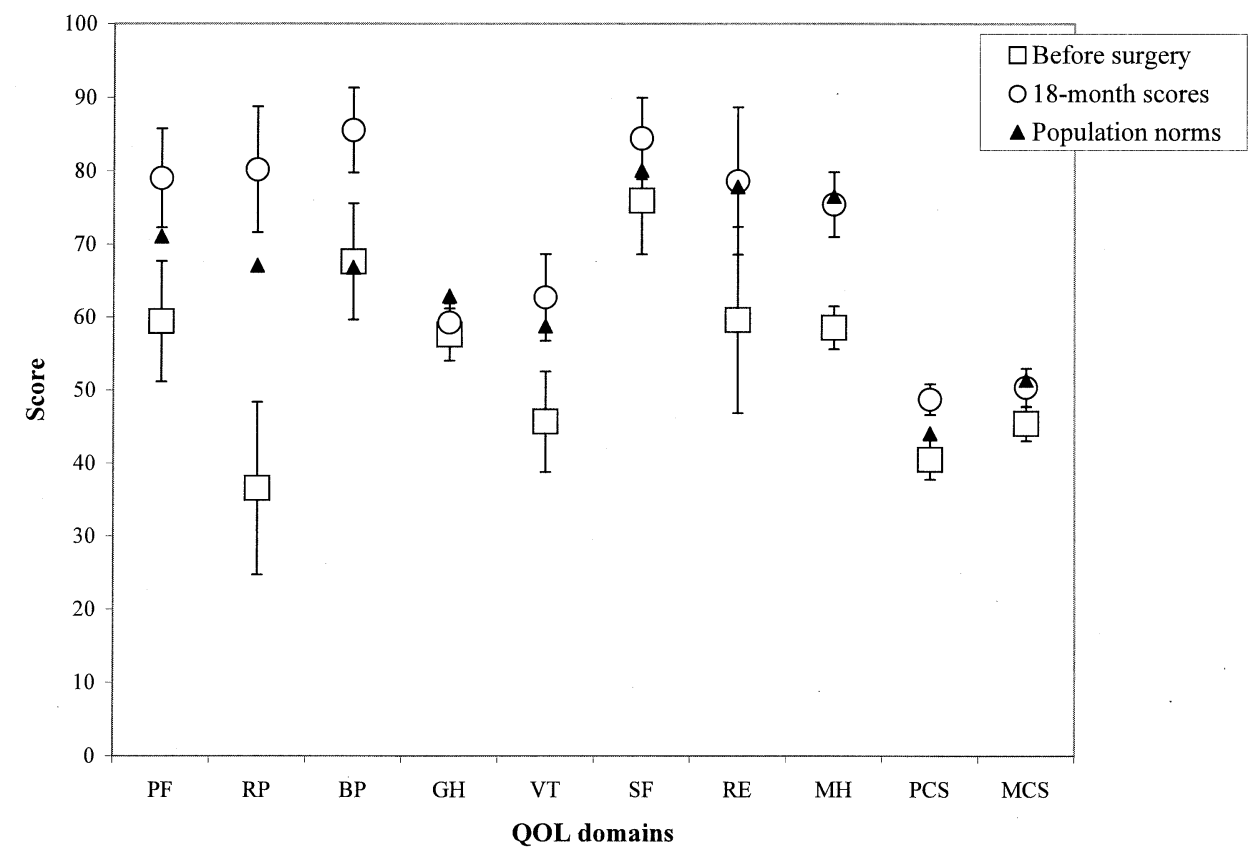

Figure 2. Unadjusted $0 \mathrm{~L}$ scores with $95 \%$ confidence intervals in patients receiving mechanical implants. White boxes represent preoperative $\mathrm{OOL}$ scores, white circles represent 18-month follow-up QOL scores, and black triangles represent US age-adjusted population norms for mechanical implant group. BP, Bodily Pain; GH, General Health; MCS, Mental Component Summary; MH, Mental Health; PCS, Physical Component Summary; PF, Physical Functioning; $Q 0 L$, quality of life; $R E$, Role Emotional; RP, Role Physical; SF, Social Functioning; VT, Vitality. 
TABLE 3. Adjusted improvements from the baseline in 00L domains and component scales for tissue and mechanical implant recipients at 18 months following surgery

\begin{tabular}{lcccc}
\hline $\begin{array}{l}\text { QOL } \\
\text { scales }\end{array}$ & $\begin{array}{c}\text { Tissue } \\
\text { implant }\end{array}$ & $\begin{array}{c}\text { Mechanical } \\
\text { implant }\end{array}$ & $\begin{array}{c}\text { Difference } \\
\text { (mean, 95\% CI) }\end{array}$ & $\boldsymbol{P}^{*}$ \\
\hline PF & 16.7 & 19.2 & $2.5(-13.1-8.0)$ & .6 \\
RP & 21.3 & 38.3 & $17.0(-33.8--0.34)$ & .046 \\
BP & 4.8 & 11.8 & $7.0(-17.1-3.1)$ & .2 \\
GH & 0.5 & 1.3 & $0.8(-4.4-2.8)$ & .6 \\
VT & 9.9 & 10.1 & $0.1(-9.4-9.1)$ & 1.0 \\
SF & -0.9 & 0.8 & $1.7(-11.7-8.2)$ & .7 \\
RE & -2.1 & 5.5 & $7.6(-24.2-8.9)$ & .4 \\
MH & 18.2 & 16.5 & $1.8(-5.7-9.2)$ & .6 \\
PCS & 4.2 & 7.3 & $3.1(-6.7-0.5)$ & .1 \\
MCS & 3.3 & 2.5 & $0.8(-3.5-5.1)$ & .7 \\
\hline
\end{tabular}

$B P$, Bodily Pain; $C l$, confidence interval; $G H$, General Health; $M C S$, Mental Component Summary; $M H$, Mental Health; PCS, Physical Component Summary; $P F$, Physical Functioning; $Q 0 L$, quality of life; $R E$, Role Emotional; $R P$, Role Physical; $S F$, Social Functioning; VT, Vitality.

Note. Least-square means presented here are useful measures for $00 \mathrm{~L}$ score comparisons but not for evaluation of absolute $00 \mathrm{~L}$ improvements. Unadjusted improvements from baseline shown in Table 2 and Figures 1 and 2 should be used for the evaluation of absolute improvements. Improvements are based on analysis of covariance (least square means) model adjusting for the baseline score, age, gender, history of myocardial infarction, peripheral vascular disease, New York Heart Association class, aortic stenosis, and the procedure type (isolated valve or simultaneous valve and coronary artery bypass graft surgery).

${ }^{*} P$ value for the difference between the least-square means.

ments from the baseline for patients receiving mechanical implants compared with those receiving tissue implants (Table 2). However, these differences in absolute improvements were less than $0.5 \mathrm{SD}$.

At baseline, both the tissue and mechanical implant groups tended to have lower mean QOL scores in most domains relative to their respective US population norms. Exceptions included the BP and GH scales in the tissue implant group and the BP, GH, and SF scales in the mechanical implant group, which were comparable to those of population norms (Figures 1 and 2). In contrast, postoperative QOL scores in both groups were similar to US population norms and in some instances were higher.

After adjusting for preoperative QOL scores, age, gender, history of MI, PVD, NYHA class, aortic stenosis, and procedure type (isolated valve or simultaneous valve and CABG), improvements in mean QOL scores for the tissue and mechanical implant groups were still similar. The only exception was for the RP domain, in which improvement was more favorable in the mechanical implant group (Table $3)$.

\section{Discussion}

In this study, we found that improvements in QOL from the baseline at 18 months following aortic valve surgery were similar in patients receiving tissue and mechanical valve implants. In addition, although the mean scores before surgery for both groups were lower relative to US population norms, at 18 months after surgery they were greatly improved and generally comparable to US population norms.

Our results are generally consistent with and extend the findings of previous studies that have examined QOL scores in patients receiving tissue and mechanical implants or that made comparisons of preoperative and postoperative QOL scores in patients undergoing valve replacements with those of population norms. Phillips and Lansky ${ }^{16}$ were the first to demonstrate that in both tissue and mechanical valve recipients, preoperative QOL scores were generally lower than in population norms, whereas by 6 months postoperatively, the scores had improved and approximated those of the general population. However, that study was small and had a low follow-up rate, which resulted in power limitations that prevented analyses by type of valve implant. Other crosssectional studies have confirmed the finding that tissue and mechanical implant recipients have similar QOL scores following aortic valve surgery. ${ }^{6,7}$ Finally, a prospective study ${ }^{9}$ addressing change in QOL at 3 months postoperatively found no differences in improvements in QOL scores reported by tissue and mechanical valve recipients. Although these individual studies had a number of limitations including significant losses to follow-up, ${ }^{16}$ inconsistent time of QOL assessment postsurgery, ${ }^{7}$ and small sample size, ${ }^{9}$ the consistency of the results in a variety of study designs supports the validity of the findings in the current largest prospective study to date.

In our study, although mechanical implant recipients reported greater improvement in the scale of RP (resulting in a trend toward slightly more improvements in PCS), postoperative scores for this scale as well as for others were similar to age-adjusted population norms in both the tissue and mechanical implant groups. Moreover, in the multi-item scales of PF, VT, and MH, as well as in the global physical (PCS) and mental (MCS) component scales, we found no statistically significant differences between the groups. Finally, tissue valve implant recipients were much more likely to be elderly and, despite statistical adjustment for age, possible residual confounding should favor mechanical valve implant recipients. Thus, the evidence of similar QOL benefits after tissue valve implantation is even stronger when taking into account that some small differences in QOL could potentially be age-related.

Clinical decisions regarding whether to use a tissue or a mechanical implant for aortic valve replacement are based primarily on weighing the anticoagulant-related complications of mechanical implants with the shorter implant life span of tissue implants. Lifelong anticoagulation with warfarin and international normalized ratio monitoring is required in patients receiving mechanical implants. The asso- 
ciated side effects include thromboembolism that varies from $1.4 \%$ to $6.5 \%$ per year and bleeding that varies from $0.7 \%$ to $4.8 \%$ per year. ${ }^{20}$ In contrast, thromboembolic events in tissue implant patients are lower $(0.2 \%-2.6 \%$ per year) and bleeding is rare. ${ }^{20}$ The major disadvantage of tissue implants is valve deterioration that results in reoperation. Although recent randomized trials have shown that the incidence of primary valve failure is similar in the 2 types of implants for up to 10 years, by 12 years the proportion of patients requiring reoperation is higher in tissue implant recipients. ${ }^{21,22}$ For elderly patients (over 70 years) or very high-risk patients, the choice of the type of implant should be considered less of an issue, as the probability of outliving a tissue implant is less. Further, bleeding associated with mechanical implants has been shown to be more common in the elderly, exceeding $5.6 \%$ per year, ${ }^{23,24}$ and resulting in a greater than $50 \%$ cumulative risk of experiencing a major bleed at 10 years.

\section{Strengths and Limitations}

The strengths of our study include the prospective cohort design, a relatively large sample size, and control for potential confounding variables. We examined QOL at 18 months postoperatively, thus assessing longer-term follow-up than has previously been addressed. We assessed QOL with the SF-36 questionnaire, a validated and widely used instrument. Furthermore, there was no age exclusion and older individuals were well represented. Thus, the results of our study are generalizable to elderly patients, who comprise the majority of patients undergoing aortic valve replacement. In this study we had sufficient power to determine statistical significance (with $95 \%$ confidence) of a clinically relevant $0.5 \mathrm{SD}$ difference between the valve implant groups. The confidence intervals around the estimate of the difference in QOL between the 2 types of valves were not large (less than $1 \mathrm{SD}$ ), which supports the robustness of our findings.

There are issues that should be considered in the interpretation of the results. Baseline QOL data were obtained during the first week after surgery. However, patients were asked to report their QOL in the month before surgery and we do not expect there to be differential recall bias based on the type of valve implant. We collected postoperative QOL assessments on $92 \%$ of the enrolled patients who survived to 18 months. However, 11 patients, all of whom were tissue implant recipients, died prior to 18 months of follow-up. A possible limitation of our study is that patients in the tissue implant group who died may have differed with regard to change in QOL scores compared with those who survived and were included in the change analysis. The differences in mortality between the treatment groups may reflect the older age (means: 73 versus 58 years) of the patients who received tissue valves, as these valves are more frequently selected for older patients. We did not have sufficient power to investigate mortality in this study. Age was a relatively insignificant predictor of change in QOL; however, despite some recent encouraging reports of acceptable operative mortality in the elderly, age is still one of the main predictors of early and late mortality after valve surgery. ${ }^{22,25}$ Finally, we determined QOL at 1.5 years following surgery, and although it is the longest follow-up in the literature to date, longer-term follow-up is indicated.

\section{Conclusions}

QOL scores for both tissue and mechanical valve recipients improved from baseline to 18 months postsurgery to a level, on average, comparable to population norms. Improvements in QOL appear to be similar with the 2 types of implants. These findings suggest that surgeons should continue to make decisions about whether to choose a tissue or mechanical valve implant based on factors such as the possible need for reoperation and expected tolerance of anticoagulation.

The Center for Outcomes Research and Evaluation (CORE) of Yale-New Haven Hospital collected detailed baseline demographic and clinical information for this study. We thank Maria Johnson for her excellent editorial work.

\section{References}

1. American Heart Association. 1999 heart and stroke statistical update. Dallas: American Heart Association; 1999.

2. Nicoloff DM. Quality of life in patients with bioprostheses and mechanical prostheses: evaluation of cohorts of patients aged 51-65 years at implantation: editorial comment. Circulation. 1998;98:86II-87II.

3. Palareti G, Leali N, Coccheri S, Poggi M, Manotti C, D'Angelo A, et al. Bleeding complications of oral anticoagulant treatment: an inception-cohort, prospective collaborative study (ISOCAT). Lancet. 1996; 348:423-8.

4. Teoh KH, Ivanov J, Weisel RD, Daniel LB, Darcel IC, Rakowski H. Clinical and Doppler echocardiographic evaluation of bioprosthetic valve failure after 10 years. Circulation. 1990;82:IV110-6.

5. Notzold A, Huppe M, Schmidtke C, Blomer P, Uhlig T, Sievers HH. Quality of life in aortic valve replacement: pulmonary autografts versus mechanical prostheses. J Am Coll Cardiol. 2001;37:1963-6.

6. Myken P, Larsson P, Larsson S, Berggren H, Caidahl K. Similar quality of life after heart valve replacement with mechanical or bioprosthetic valves. J Heart Valve Dis. 1995;4:339-45.

7. Perchinsky M, Henderson C, Jamieson WR, Anderson WN Jr, Lamy A, Lowe N, et al. Quality of life in patients with bioprostheses and mechanical prostheses: evaluation of cohorts of patients aged 51 to 65 years at implantation. Circulation. 1998;98:II81-6.

8. Bonow RO, Carabello B, de Leon AC Jr, Edmunds LH Jr, Fedderly $\mathrm{BJ}$, Freed MD, et al. ACC/AHA guidelines for the management of patients with valvular heart disease: a report of the American College of Cardiology/American Heart Association Task Force on Practice Guidelines (Committee on Management of Patients with Valvular Heart Disease). J Am Coll Cardiol. 1998;32:1486-588.

9. Goldsmith IR, Lip GY, Patel RL. A prospective study of changes in patients' quality of life after aortic valve replacement. J Heart Valve Dis. 2001;10:346-53.

10. McHorney CA, Ware JE Jr, Lu JFR, Sherbourne CD. The MOS 36 Item Short Form Health Survey (SF 36): tests of data quality, scaling assumptions, and reliability across diverse patient groups. Med Care. 1994;32:40-66.

11. Beaton DE, Hogg-Johnson S, Bombardier C. Evaluating changes in 
health status: reliability and responsiveness of five generic health status measures in workers with musculoskeletal disorders. J Clin Epidemiol. 1997;50:79-93.

12. The Bypass Angioplasty Revascularization Investigation (BARI) Investigators. Comparison of coronary bypass surgery and angioplasty in patients with multivessel disease. N Engl J Med. 1996;335:217-25.

13. Rumsfeld JS, Whinney SM, McCarthy M Jr, Shroyer AL, Villanueva $\mathrm{CB}$, O'Brien $\mathrm{M}$, et al. Health-related quality of life as a predictor of mortality following coronary artery bypass graft surgery. JAMA. 1999; 281:1298-303

14. Bungay KM, Ware JE. Measuring and monitoring health-related quality of life: current concepts. Kalamazoo (Mich): The Upjohn Company; 1993.

15. Ware JE Jr, Kosinski M, Keller SD. SF-36 Physical and Mental Health Summary Scales: a user's manual. Boston (Mass): The Health Institute, New England Medical Center; 1994.

16. Phillips RC, Lansky DJ. Outcomes management in heart valve replacement surgery: early experience. J Heart Valve Dis. 1992;1:42-50.

17. Ware JE Jr, Snow K, Kosinski M, Gandek M. SF-36 Health survey: manual and interpretation guide. Boston (Mass): The Health Institute, New England Medical Center; 1997.

18. Clark RE. Definitions of terms of the Society of Thoracic Surgeons National Cardiac Surgery Database. Ann Thorac Surg. 1994;58:271-3.

19. Revicki DA, Osoba D, Fairclough D, Barofsky I, Berzon R, Leidy NK, et al. Recommendations of health-related quality of life research to support labeling and promotional claims in the United States. Qual Life Res. 2000;9:887-900.

20. Stein PD, Alpert JS, Bussey HI, Dalen JE, Turpie AG. Antithrombotic therapy in patients with mechanical and biological prosthetic heart valves. Chest. 2001;119:220S-227S.

21. Hammermeister K, Sethi GK, Henderson WG, Grover FL, Oprian C, Rahimtoola $\mathrm{SH}$. Outcomes 15 years after valve replacement with a mechanical versus a bioprosthetic valve: final report of the Veterans Affairs Randomized Trial. J Am Coll Cardiol. 2000;36:1152-8.

22. Peterseim DS, Cen YY, Cheruvu S, Landolfo K, Bashore TM, Lowe $\mathrm{JE}$, et al. Long-term outcome after biologic versus mechanical aortic valve replacement in 841 patients. J Thorac Cardiovasc Surg. 1999; 117:890-7

23. Cannegieter SC, Rosendaal FR, Wintzen AR, van der Meer FJ, Vandenbroucke JP, Briet E. Optimal anticoagulant therapy in patients with mechanical heart valves. $N$ Engl J Med. 1995;333:11-7.

24. Beyth RJ, Quinn L, Landefeld CS. A multicomponent intervention to prevent major bleeding complications in older patients receiving warfarin. A randomized, controlled trial. Ann Intern Med. 2000;133:68795.

25. Hannan EL, Racz MJ, Jones RH, Gold JP, Ryan TJ, Hafner JP, et al. Predictors of mortality for patients undergoing cardiac valve replacements in New York State. Ann Thorac Surg. 2000;70:1212-8.

Access to The Journal of Thoracic and Cardiovascular Surgery Online is reserved for print subscribers!

Full-text access to The Journal of Thoracic and Cardiovascular Surgery Online is available for all print subscribers. To activate your individual online subscription, please visit The Journal of Thoracic and Cardiovascular Surgery Online, point your browser to http://www.mosby.com/itcvs, follow the prompts to activate your online access, and follow the instructions. To activate your account, you will need your subscriber account number, which you can find on your mailing label (note: the number of digits in your subscriber account number varies from 6 to 10 ). See the example below in which the subscriber account number has been circled:

\section{Sample mailing label}

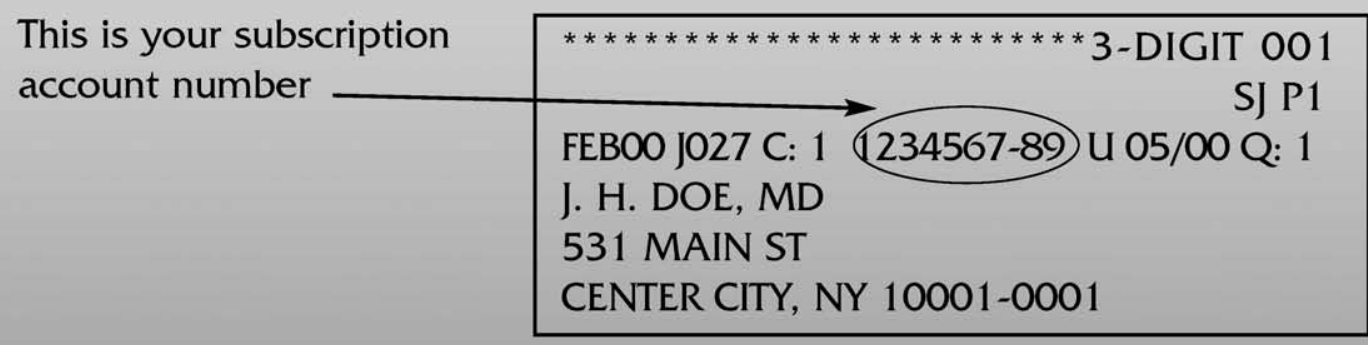

Personal subscriptions to The Journal of Thoracic and Cardiovascular Surgery Online are for individual use only and may not be transferred. Use of The Journal of Thoracic and Cardiovascular Surgery Online is subject to agreement to the terms and conditions as indicated online. 